\title{
Multirecombinant Enterovirus A71 Subgenogroup C1 Isolates Associated with Neurologic Disease, France, 2016-2017
}

\section{Stéphanie Tomba Ngangas, Alexander Lukashev, Gwendoline Jugie, Olga Ivanova, Jean-Michel Mansuy, Catherine Mengelle, Jacques Izopet, Anne-Sophie L'honneur, Flore Rozenberg, David Leyssene, Denise Hecquet, Stéphanie Marque-Juillet, David Boutolleau, Sonia Burrel, Hélène Peigue-Lafeuille, Christine Archimbaud, Kimberley Benschop, Cécile Henquell, Audrey Mirand, Jean-Luc Bailly}

In 2016, an upsurge of neurologic disease associated with infection with multirecombinant enterovirus A71 subgenogroup $C 1$ lineage viruses was reported in France. These viruses emerged in the 2000s; 1 recombinant is widespread. This virus lineage has the potential to be associated with a long-term risk for severe disease among children.

$\mathrm{E}$ nterovirus A71 (EV-A71) comprises 7 genogroups (AG) and various subgenogroups (e.g., B0-B5, C1-C5) (1). B4, B5, and C4 viruses circulate mainly in Asia, and $\mathrm{C} 1$ and $\mathrm{C} 2$ viruses have been detected in Europe (2). In

Author affiliations: Université Clermont Auvergne,

Clermont-Ferrand, France (S. Tomba Ngangas, G. Jugie, H. Peigue-Lafeuille, C. Archimbaud, C. Henquell, A. Mirand, J.-L. Bailly); Sechenov University, Moscow, Russia (A. Lukashev, O. Ivanova); Chumakov Federal Scientific Center for Research and Development of Immune-and-Biological Products, Moscow (O. Ivanova); Centre Hospitalier Universitaire de Toulouse, Toulouse, France (J.-M. Mansuy, C. Mengelle, J. Izopet); Assistance Publique-Hôspitaux de Paris Cochin, Paris, France (A.-S. L'honneur, F. Rozenberg); Centre Hospitalier de la Côte Basque, Bayonne, France (D. Leyssene); Centre Hospitalier Universitaire Amiens, Amiens, France (D. Hecquet); Centre Hospitalier de Versailles, Le Chesnay, France (S. Marque-Juillet); Assistance Publique-Hôspitaux de Paris Pitié-Salpêtrière-Charles Foix, Paris (D. Boutolleau, S. Burrel); CHU Clermont-Ferrand, Clermont-Ferrand ( $\mathrm{H}$. Peigue-Lafeuille, C. Archimbaud,

C. Henquell, A. Mirand, J.-L. Bailly); National Institute for Public Health and the Environment, Bilthoven, the Netherlands (K. Benschop)

DOI: https://doi.org/10.3201/eid2506.181460
2016, an upsurge in neurologic manifestations of enterovirus infection was reported in France (3). These cases were associated with an emerging lineage of subgenogroup $\mathrm{C} 1$ enteroviruses first reported in 2015 in Germany and later in Spain and 4 other countries (Figure 1, panel A) (4-8). Our aim was to obtain the full genomes of the viruses from the specimens collected in France and track down the origin of this emerging lineage, hereafter referred to as C1v2015.

\section{The Study}

According to consolidated data recorded from the French Enterovirus Surveillance Network, 77 laboratory-confirmed cases of C1v2015 infection occurred during MarchOctober 2016; in comparison, 136 EV-A71 infections of all genogroups combined were recorded during 2010-2015. The C1v2015 cases were widespread throughout France and associated with various clinical manifestations, including meningitis, cerebellitis, encephalitis, and myelitis, as well as hand, foot and mouth disease (HFMD) (Figure 1, panels B, C). One fatal case resulted from HFMD and cardiorespiratory failure. We analyzed 32 clinical specimens available from 25 patients reported as having a C1v2015 infection in 2016 and 2017 (Table 1; Appendix Table 1, https://wwwnc.cdc.gov/EID/article/25/6/18-1460-App1. pdf). Specimens and clinical data were collected during routine clinical work-up and epidemiologic surveillance, and patient data were deidentified before this study was conducted. The study was approved by the review board Comité de Protection des Personnes Sud-Est VI (no. 2018/ CE44) in Clermont-Ferrand, France. The study population comprised 16 hospitalized children (median age 0.1 years), 4 children seen via ambulatory care (median age 1.8 years), and 5 children with asymptomatic infection (median age 1.4 years) in a childcare facility placed under community surveillance. We obtained the complete genomes, including the full 5' and $3^{\prime}$ untranslated regions (UTRs), of 18 of 20 specimens and partial genomes of 2 of 20 specimens $(2,893-$ nt and 4,380-nt long) acquired from 18 children (Appendix) (2). We also determined the genomes of 12 isolates recovered during routine enterovirus surveillance to investigate their genetic relationships with C1v2015 (Appendix Table 2 ); we selected these viruses on the basis of previous exploratory investigations of their partial sequences $(2,9,10)$. 


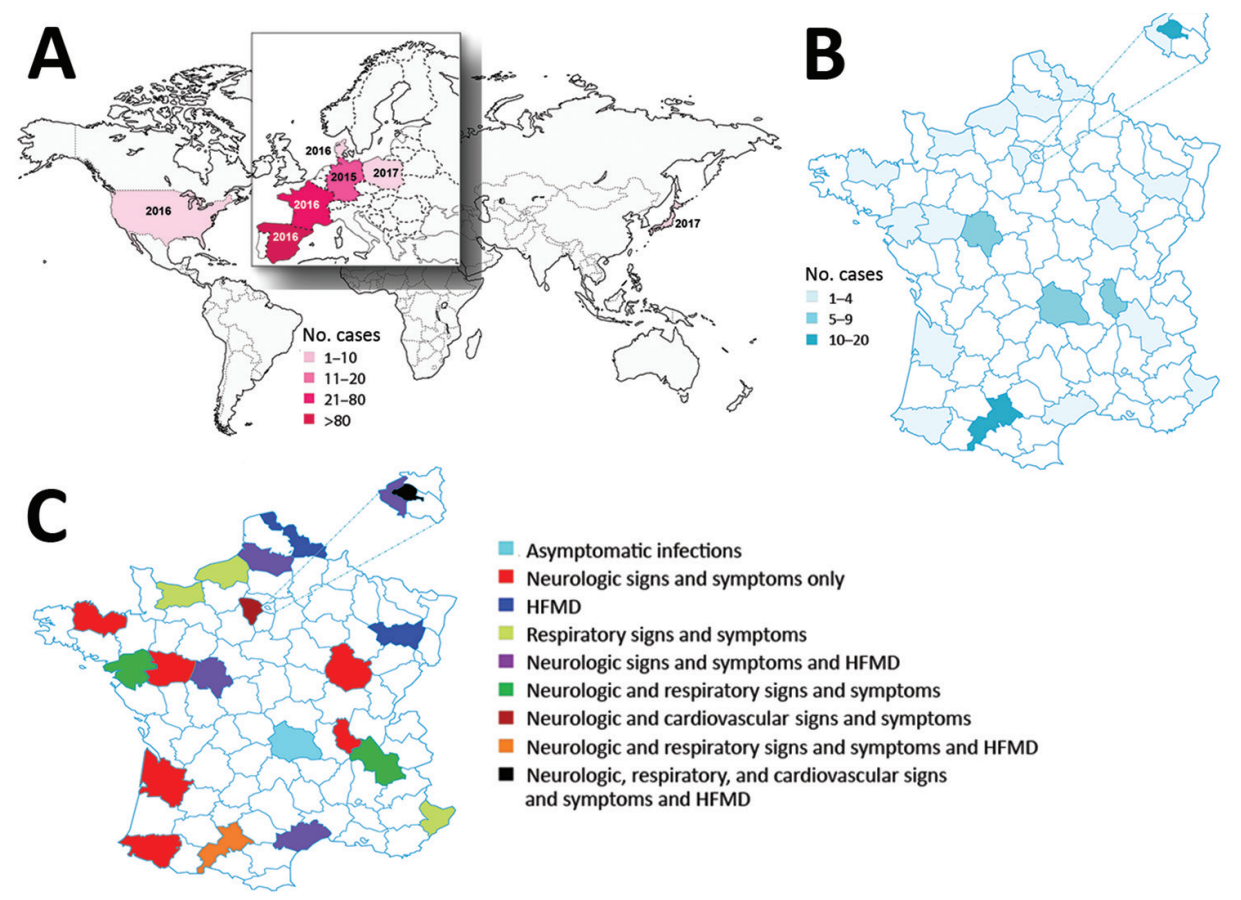

Figure 1. Geographic locations and numbers of enterovirus A71 (EV-A71) subgenogroup C1v2015 infections reported during 2015-2017. A) Countries in which EV-A71 C1v2015 was reported. The year the virus was first reported is indicated. The size of Europe is increased for easier visualization. B) Geographic distribution and number of cases of EV-A71 C1v2015 infection reported in hospitals, by department, France, 2016-2017. C) Geographic distribution of clinical manifestations associated with EV-A71 C1v2015 infection reported in hospitals, by department, France, 2016-2017. The size of a select set of departments is enlarged for easier visualization. HFMD, hand, foot and mouth disease.

\begin{tabular}{|c|c|c|c|c|c|c|}
\hline $\begin{array}{l}\text { Patient } \\
\text { no. }\end{array}$ & $\begin{array}{c}\text { Specimen } \\
\text { no. }\end{array}$ & Care setting (City) & Clinical diagnosis & Specimen material & Collection date & $\mathrm{C}_{\mathrm{t}}$ \\
\hline 01 & $01 \dagger$ & Hospital (Toulouse) & Acute meningitis & Throat swab & 2016 May 3 & 25 \\
\hline 02 & 02 & Hospital (Toulouse) & Fever & Nasopharyngeal aspirate & 2016 May 19 & 30 \\
\hline 02 & 03 & Hospital (Toulouse) & Fever & Feces & 2016 May 19 & 31 \\
\hline 03 & 04 & Hospital (Paris) $\ddagger$ & Fever & Plasma & 2016 Jun 7 & 37 \\
\hline 04 & 05 & Hospital (Paris) $\ddagger$ & Fever & Plasma & 2016 Jun 10 & 32 \\
\hline 05 & 06 & Hospital (Bayonne) & Encephalitis & Cerebrospinal fluid & 2016 Jun 12 & 35 \\
\hline 05 & $07 \dagger$ & Hospital (Bayonne) & Encephalitis & Throat swab & 2016 Jun 24 & 35 \\
\hline 05 & 08 & Hospital (Bayonne) & Encephalitis & Rectal swab & 2016 Jun 24 & 35 \\
\hline 06 & 09 & Hospital (Toulouse) & Infant fever & Feces & 2016 Jul 10 & 31 \\
\hline 07 & $10 \dagger$ & Hospital (Toulouse) & Sepsis-like disease & Throat swab & 2016 Aug 10 & 24 \\
\hline 07 & $11 \dagger$ & Hospital (Toulouse) & Sepsis-like disease & Nasopharyngeal aspirate & 2016 Aug 10 & NR \\
\hline 08 & $12 \dagger$ & Hospital (Paris) $\ddagger$ & Convulsions & Nasopharyngeal aspirate & 2016 Aug 11 & 28 \\
\hline 09 & $13 \S$ & Ambulatory (Mirecourt) & HFMD & Mouth swab & 2016 Aug 30 & 32 \\
\hline 10 & $14 \dagger$ & Ambulatory (Mirecourt) & HFMD & Throat swab & 2016 Aug 30 & 29 \\
\hline 11 & $15 \dagger$ & Hospital (Paris) $\ddagger$ & Fever, hypotonia & Blood & 2016 Sep 5 & 30 \\
\hline 12 & $16 \S$ & Hospital (Toulouse) & Acute meningitis, HFMD & Throat swab & 2016 Sep 7 & 33 \\
\hline 13 & $17 \dagger$ & Ambulatory (Toulouse) & HFMD & Mouth swab & 2016 Sep 14 & 29 \\
\hline 14 & $18+$ & Hospital (Paris) $\ddagger$ & Fever & Feces & 2016 Sep 27 & 20 \\
\hline $15 \pi$ & $19 \dagger$ & Daycare (Volvic) & NR & Feces & 2016 Oct 4 & 29 \\
\hline $16 \pi$ & $20 \dagger$ & Daycare (Volvic) & NR & Feces & 2016 Oct 4 & 31 \\
\hline $17 \pi$ & $21 \dagger$ & Daycare (Volvic) & NR & Feces & 2016 Oct 4 & 31 \\
\hline $18 \pi$ & $22 \dagger$ & Daycare (Volvic) & NR & Feces & 2016 Oct 4 & 29 \\
\hline 19ा & $23 \dagger$ & Daycare (Volvic) & NR & Feces & 2016 Oct 4 & 31 \\
\hline 20 & 24 & Hospital (Toulouse) & Sepsis-like disease & Throat swab & 2016 Oct 5 & 33 \\
\hline 21 & 25 & Hospital (Versailles) & Diarrhea & Cerebrospinal fluid & 2016 Oct 9 & 35 \\
\hline 22 & 26 & Hospital (Toulouse) & Acute meningitis, cerebellitis & Throat swab & 2016 Oct 10 & 36 \\
\hline 22 & 27 & Hospital (Toulouse) & Acute meningitis, cerebellitis & Feces & 2016 Oct 10 & 30 \\
\hline 23 & $28 \dagger$ & Hospital (Toulouse) & Fever & Throat swab & 2016 Oct 11 & 27 \\
\hline 23 & 29 & Hospital (Toulouse) & Fever & Feces & 2016 Oct 12 & 29 \\
\hline 24 & $30 \dagger$ & Hospital (Amiens) & Myelitis & Nasopharyngeal swab & 2016 Oct 18 & 30 \\
\hline 24 & $31 \dagger$ & Hospital (Amiens) & Myelitis & Feces & 2016 Oct 20 & 33 \\
\hline 25 & $32 \dagger$ & Ambulatory (Montesson) & Atypical HFMD, herpangina & Throat swab & 2017 Jul 3 & 22 \\
\hline & & & & data including Gent & sion nos. $C_{t}$, cy & \\
\hline
\end{tabular}


We performed whole-genome sequence analyses as previously described (11) to identify which viruses were the closest relatives of $\mathrm{C} 1 \mathrm{v} 2015$. The $\mathrm{C} 1 \mathrm{v} 2015$ genome appears to be a mosaic comprising 4 modules defined by distinct patterns of similarity possibly arising through recombination (Figure 2, panel A). The nucleotide similarity patterns for module 2 (genomic region P1 comprising 4 capsid protein genes) suggest this region was inherited en bloc from an earlier subgenogroup $\mathrm{C} 1$ lineage. We used genomic region $\mathrm{P} 1$ to determine the evolutionary

Figure 2. Nucleotide similarity and phylogenetic analyses of EV-A71 subgenogroup C1v2015 isolates, France, 2016-2017, constructed to determine temporal origin of C1v2015 lineage. A) Nucleotide similarity patterns between EV-A71 C1v2015 and other EV-A lineages indicate the C1v2015 genome has a mosaic structure. A schematic diagram of the enterovirus genome is shown at the bottom of the panel. Four genomic modules (labeled at top of panel) with different genetic origins are identified; genomic modules are indicated in dark gray. The arrowhead indicates a previously undescribed recombinant lineage of C1v2015 (Appendix Figure 2, https://wwwnc.cdc.gov/ EID/article/25/6/18-1460-App1.pdf). B) Phylogenetic tree constructed by using genomic region $\mathrm{P} 1$, encoding capsid proteins VP1-VP4, and methods described earlier (11). We performed this analysis with 85 sequences assigned to the EV-A71 C1 and C1v2015 lineages. Tree shows the temporal distribution of lineages, including the emergence of lineage C1v2015. C) Phylogenetic tree constructed by using 3Dpol, encoding the viral RNA polymerase common to C1v2015 and several CV-A strains. The dataset comprised 70 sequences: $24 \mathrm{CV}-\mathrm{A}$ (including 5 from this study), 14 EV-A71 C1 (including 6 from this study), 12 publicly available C1v2015, and 20 C1v2015 from this study. Recombination analyses provided no evidence of internal breakpoints within the sequences. $\mathrm{N} 1$ represents the time to most recent common ancestor (MRCA) of all included EV-A71 C1v2015 isolates except the virus from patient 14; N2 in panel B represents the MRCA of all EV-A71
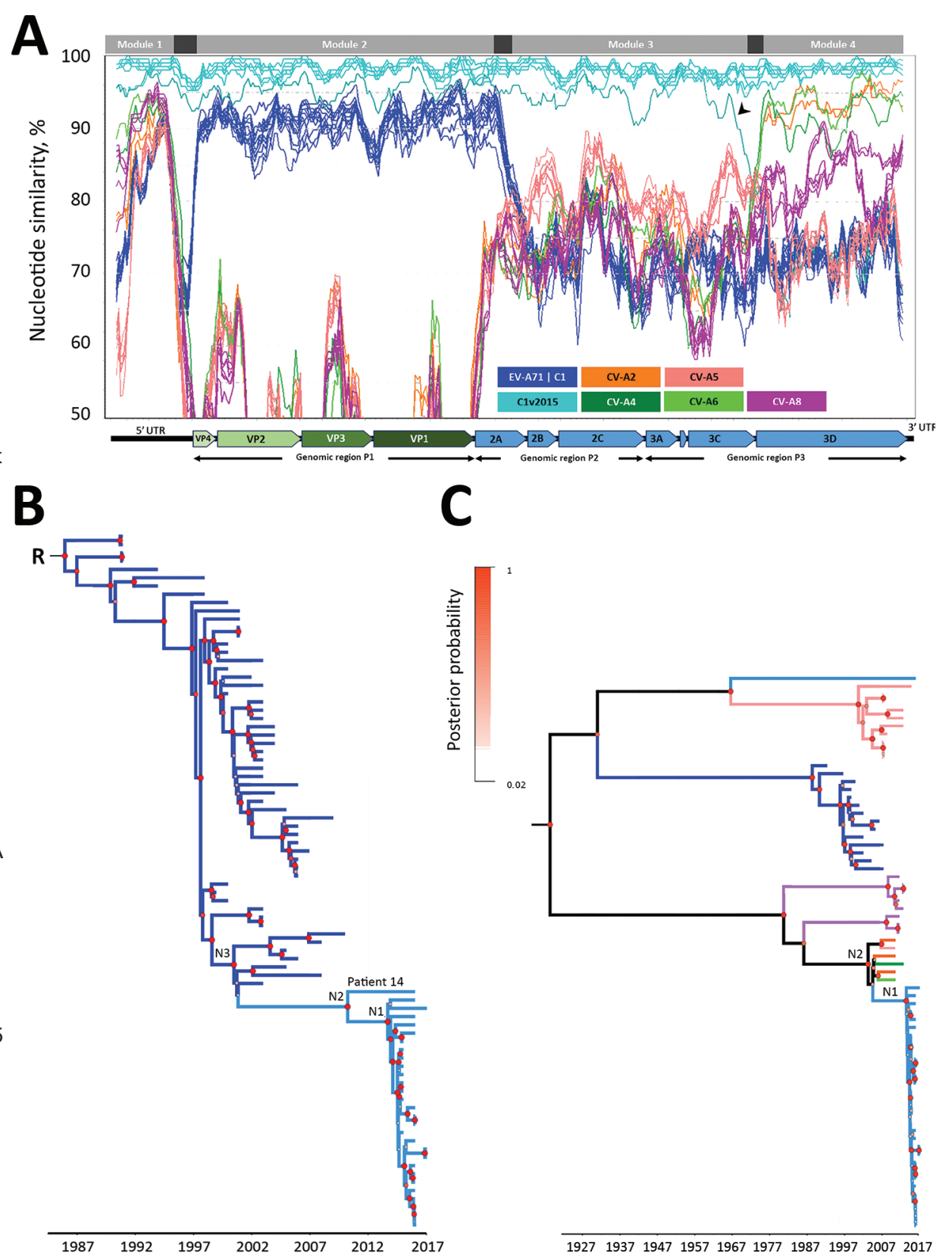

C1v2015 isolates, including the

virus from patient 14; N2 in panel C represents the MRCA of EV-A71 C1v2015 and its parent C1 lineage; and N3 represents the MRCA of EV-A71 C1v2015 and its parent C1 lineage (see Table 2). Diameters of circles at nodes reflect posterior probability. Branches of trees are color coded according to virus lineage as indicated in panel A. C1v2015, enterovirus subgenogroup C1 strain discovered in 2015; CV-A, coxsackievirus genogroup A; EV-A71C1, enterovirus A71 subgenogroup C1; N, node; UTR, untranslated region; VP, viral protein. An expanded version of this figure and legend describing complete methods and providing details of the trees in panels $B$ and $C$ is available online (https://wwwnc.cdc.gov/EID/article/25/6/18-1460-F2.htm). 
relatedness between $\mathrm{C} 1 \mathrm{v} 2015$ and earlier $\mathrm{C} 1$ viruses and to date when the upsurge of $\mathrm{C} 1 \mathrm{v} 2015$ infections began in Europe (Figure 2, panel B). All C1v2015 viruses clustered in a lineage distinct from that comprising the $\mathrm{C} 1$ viruses reported during 1991-2010. The nucleotide substitution rate of C1v2015 (5.2238 [95\% highest probability density HPD interval 4.124-6.3737] $\times 10^{-3} \mathrm{nt}$ substitutions/y) and earlier C1 lineages (4.6302 [95\% HPD interval 4.17695.1353] $\times 10^{-3} \mathrm{nt}$ substitutions/y) was similar. All of the $\mathrm{P} 1$ sequences from these viruses, except that of the virus from patient 14 , had a maximum nucleotide sequence difference from each other of $2 \%$; the P1 sequence of the virus from patient 14 differed from that of other C1v2015 viruses by $4.8 \%$. The close genetic relatedness between the C1v2015 sequences reported during 2015-2017 in France, Germany, Japan, and the United States was indicative of rapid widespread transmission. We estimated that interpersonal transmission of this lineage began during 2009-2011 (Table 2; Figure 2, panel B) and that its spread was sustained during 2013-2014, just 1-2 years before C1v2015 was first reported. The most recent common ancestor between $\mathrm{C} 1 \mathrm{v} 2015$ and earlier $\mathrm{C} 1$ viruses was dated to 2000-2002. Seven EV-A71 subgenogroup C1 viruses from Africa and Europe were located at the base of the C1v2015 lineage (Figure 2, panel B), suggesting that the C1 strain involved in the emergence of C1v2015 was circulating in this region during the 2000s.

The C1v2015 genomic module 4 comprises the entire 3Dpol gene and has a 90\%-95\% nucleotide similarity with 4 distinct EV-A genomes: coxsackievirus A2 (CVA2) and CV-A5 from Russia, CV-A4 from China, and CV-A6 from Turkmenistan (Figure 2, panel A). We performed another phylogenetic analysis to assess the temporal origin of C1v2015 using this module. With the 3Dpol phylogenetic analysis, we estimated that $\mathrm{C} 1 \mathrm{v} 2015$ began spreading in 2010-2014 (Table 2; Figure 2, panel C), an estimate similar to that calculated with the $\mathrm{P} 1$ phylogeny. The nucleotide substitution rates with this analysis were also similar (C1v2015 3.7689 [95\% HPD interval 1.3003$6.5838] \times 10^{-3} \mathrm{nt}$ substitutions/y and $\mathrm{C} 13.6318$ [95\% HPD interval 1.6064-6.2072] $\times 10^{-3} \mathrm{nt}$ substitutions/y). Whole-genome sequencing analysis showed that the isolate from patient 14 (14|COC286037|FRA|2016) shared distinct 3Dpol genes with other C1v2015 viruses (Appendix Figure 1). Overall, data indicate that the virus from patient 14 was an early recombinant of the C1v2015 lineage (Appendix Figure 2).

Within genomic module 1 ( $5^{\prime}$ UTR, first $600 \mathrm{nt}$ ), we found areas of moderate nucleotide similarity $(90 \%-95 \%)$ between the C1v2015 genome and the CV-A6 and CVA8 genomes and lower similarity $(<88 \%)$ with the EVA71 subgenogroup $\mathrm{C} 1$ genomes (Figure 2, panel A). The C1v2015 5' UTR was therefore inherited from an EV-A
Table 2. Estimation of year of MRCA of EV-A71 subgenogroup C1v2015 lineage by using different enteroviruses*

\begin{tabular}{lcc}
\hline & \multicolumn{2}{c}{ Year of MRCA (95\% HPD interval) } \\
\cline { 2 - 3 } Node & Genomic region P1 & 3Dpol gene \\
\hline $1 \ddagger$ & $2013.6(2013.2-2014.1)$ & $2013.6(2012.9-2014.3)$ \\
$2 \S$ & $2010.2(2009-2011.3)$ & $2004.1(2001.7-2006.2)$ \\
3 I & $2000.5(2000.1-2001.6)$ & ND \\
Root & $1986(1984.7-1987.3)$ & ND \\
\hline
\end{tabular}

*EV-A71, enterovirus A71; HPD, highest probability density; MRCA, most recent common ancestor; ND, not done.

†MRCAs were determined for nodes and root in Figure 2.

¥Node 1 represents the MRCA of all included EV-A71 C1v2015 isolates except the virus from patient 14

§For genomic region $\mathrm{P} 1$, node 2 represents the MRCA of all EV-A71 C1v2015 isolates, including the virus from patient 14. For 3Dpol gene, node 2 represents the MRCA of EV-A71 C1v2015 and its parent C1 lineage.

TNode 3 represents the MRCA of EV-A71 C1V2015 and its parent C1 lineage.

lineage virus but not from the $\mathrm{C} 1$ ancestors that provided the capsid region. The pattern of sequence variation in the $5^{\prime}$ UTR precludes the possibility of analysis with a molecular clock.

The genomic module 3 of C1v2015 had low similarity with all the publicly available EV-A genomes; thus, the precise origin remains unknown (Figure 2, panel A). The highest nucleotide similarity scores $(<90 \%$ with CVA5 genomes) indicate only a distant genetic relationship. We conclude that genes $2 \mathrm{~A}$ (except the $5^{\prime}$ terminus), 2B, $2 \mathrm{C}$, and $3 \mathrm{~A}-3 \mathrm{C}$ were transferred into the $\mathrm{C} 1 \mathrm{v} 2015$ genome from a previously unreported lineage.

\section{Conclusions}

Thirty years after the outbreaks in central Europe $(12,13)$, the 2016 upsurge of infections is a reminder that EV-A71 is of growing public health concern. After the B5 and C4 subgenogroup upsurges, C1v2015 is the latest example of an emerging recombinant EV-A71 associated with neurologic manifestations. Recombination, which frequently occurs in enteroviruses, is considered a factor driving this viral emergence $(14,15)$. Compared with earlier circulating lineages of EV-A71, C1v2015 is a multirecombinant that arose through complete shuffling of all nonstructural genomic regions, although the capsid genes are phylogenetically typical of $\mathrm{C} 1$ viruses. Shuffling involved $\geq 2$ recombination events with EV-A genomes before the emergence of C1v2015 as a lifethreatening pathogen (Appendix Figure 2). From a public health perspective, the spread of C1v2015 could have resulted from acquired genomic features, notably a unique combination of the 5' UTR and 3Dpol gene, because recombination events clearly preceded the extensive circulation of C1v2015. The mosaic structure of the genome indicates that C1v2015 is an integral part of a large recombination network including multiple EV-A viruses transmitted in Eurasia. Given the propensity of enteroviruses to recombine their genomes and spread rapidly across distant countries $(2,11)$ and that $\mathrm{C} 1 \mathrm{v} 2015$ circulation continued throughout 
2017 and 2018 in France, we need to determine if this virus is associated with a long-term recurrent risk for severe disease in the pediatric population through sharing data from global surveillance.

\section{Acknowledgments}

The authors are indebted to Patrice Bouissou, Annick Givois, and Martine Wagner-Vaucard, who obtained samples in children with hand, foot and mouth disease. We acknowledge the technical contribution of Jeroen Cremer, Adeline Duard, Nathalie Rodde, and Isabelle Simon for helpful assistance with molecular typing and sequencing. We thank Jeffrey Watts for help in preparing the manuscript in English.

Financial support was provided by the University Clermont Auvergne, France.

\section{About the Author}

Ms. Tomba Ngangas is a doctoral candidate at the Université Clermont Auvergne in Clermont-Ferrand, France. Her research interests are in characterizing viruses that cause neurologic disease and hand, foot and mouth disease.

\section{References}

1. Bessaud M, Razafindratsimandresy R, Nougairède A, Joffret ML, Deshpande JM, Dubot-Pérès A, et al. Molecular comparison and evolutionary analyses of VP1 nucleotide sequences of new African human enterovirus 71 isolates reveal a wide genetic diversity. PLoS One. 2014;9:e90624. http://dx.doi.org/10.1371/ journal.pone. 0090624

2. Hassel C, Mirand A, Lukashev A, TerletskaiaLadwig E, Farkas A, Schuffenecker I, et al. Transmission patterns of human enterovirus 71 to, from, and among European countries, 2003 to 2013. Euro Surveill. 2015;20:30005. http://dx.doi.org/10.2807/1560-7917. ES.2015.20.34.30005

3. Antona D, Kossorotoff M, Schuffenecker I, Mirand A, Leruez-Ville M, Bassi C, et al. Severe paediatric conditions linked with EV-A71 and EV-D68, France, May to October 2016. Euro Surveill. 2016;21:30402. http://dx.doi.org/10.2807/1560-7917. ES.2016.21.46.30402

4. Böttcher S, Obermeier PE, Neubauer K, Diedrich S; Laboratory Network for Enterovirus Diagnostics. Recombinant enterovirus A71 subgenogroup C1 strains, Germany, 2015. Emerg Infect Dis. 2016;22:1843-6. http://dx.doi.org/10.3201/eid2210.160357

5. Karrasch M, Fischer E, Scholten M, Sauerbrei A, Henke A, Renz DM, et al. A severe pediatric infection with a novel enterovirus A71 strain, Thuringia, Germany. J Clin Virol. 2016;84:90-5. http://dx.doi.org/10.1016/j.jcv.2016.09.007
6. Casas-Alba D, de Sevilla MF, Valero-Rello A, Fortuny C, García-García JJ, Ortez C, et al. Outbreak of brainstem encephalitis associated with enterovirus-A71 in Catalonia, Spain (2016): a clinical observational study in a children's reference centre in Catalonia. Clin Microbiol Infect. 2017;23:874-81. http://dx.doi.org/ 10.1016/j.cmi.2017.03.016

7. Wieczorek M, Purzyńska M, Krzysztoszek A, Ciąćka A, Figas A, Szenborn L. Genetic characterization of enterovirus A71 isolates from severe neurological cases in Poland. J Med Virol. 2018;90:372-6. http://dx.doi.org/10.1002/jmv.24958

8. Midgley SE, Nielsen AG, Trebbien R, Poulsen MW, Andersen PH, Fischer TK. Co-circulation of multiple subtypes of enterovirus A71 (EV-A71) genotype $\mathrm{C}$, including novel recombinants characterised by use of whole genome sequencing (WGS), Denmark 2016. Euro Surveill. 2017;22:30565. http://dx.doi.org/10.2807/1560-7917. ES.2017.22.26.30565

9. Lukashev AN, Shumilina EY, Belalov IS, Ivanova OE, Eremeeva TP, Reznik VI, et al. Recombination strategies and evolutionary dynamics of the human enterovirus A global gene pool. J Gen Virol. 2014;95:868-73. http://dx.doi.org/10.1099/ vir.0.060004-0

10. van der Sanden S, van der Avoort H, Lemey P, Uslu G, Koopmans M. Evolutionary trajectory of the VP1 gene of human enterovirus 71 genogroup B and C viruses. J Gen Virol. 2010;91:1949-58. http://dx.doi.org/10.1099/vir.0.019695-0

11. Hassel C, Mirand A, Farkas A, Diedrich S, Huemer HP, Peigue-Lafeuille H, et al.; HFMD French Study Network. Phylogeography of coxsackievirus A16 reveals global transmission pathways and recent emergence and spread of a recombinant genogroup. J Virol. 2017;91:e00630-17. http://dx.doi.org/10.1128/JVI.00630-17

12. Chumakov M, Voroshilova M, Shindarov L, Lavrova I, Gracheva L, Koroleva G, et al. Enterovirus 71 isolated from cases of epidemic poliomyelitis-like disease in Bulgaria. Arch Virol. 1979;60:329-40. http://dx.doi.org/10.1007/BF01317504

13. Nagy G, Takátsy S, Kukán E, Mihály I, Dömök I. Virological diagnosis of enterovirus type 71 infections: experiences gained during an epidemic of acute CNS diseases in Hungary in 1978. Arch Virol. 1982;71:217-27. http://dx.doi.org/10.1007/ BF01314873

14. McWilliam Leitch EC, Cabrerizo M, Cardosa J, Harvala H, Ivanova OE, Koike S, et al. The association of recombination events in the founding and emergence of subgenogroup evolutionary lineages of human enterovirus 71 . J Virol. 2012;86:2676-85. http://dx.doi.org/10.1128/JVI.06065-11

15. Kyriakopoulou Z, Pliaka V, Amoutzias GD, Markoulatos P. Recombination among human non-polio enteroviruses: implications for epidemiology and evolution. Virus Genes. 2015;50:177-88. http://dx.doi.org/10.1007/s11262-014-1152-y

Address for correspondence: Jean-Luc Bailly, Université Clermont

Auvergne, LMGE UMR 6023, Clermont-Ferrand, France;

email: j-luc.bailly@uca.fr 